\title{
ERRATUM
}

\section{Erratum zu: Stahlverstärkter Aluminiumguss}

\section{Bauraumreduzierung durch lastfallgerechte Auslegung eines Verbund-Hecklängsträgers mittels Mehrphasen-Topologieoptimierung}

\section{Dominik Schittenhelm ${ }^{1}$ (D) Andreas Burblies ${ }^{2} \cdot$ Matthias Busse $^{2}$}

Online publiziert: 1. März 2018

๑) Springer-Verlag GmbH Deutschland, ein Teil von Springer Nature 2018

\section{Erratum zu:}

Forsch Ingenieurwes 2018

https://doi.org/10.1007/s10010-018-0263-3

Die in der Originalveröffentlichung enthaltene Abbildung 1 wurde aus rechtlichen Gründen (Copyright) nachträglich wieder entfernt, ebenso wie ein Satz im Text, der auf diese Abbildung Bezug nahm.

Die nachfolgenden Abbildungen wurden entsprechend neu durchnumeriert. Ebenso wurde die ursprüngliche Abbildung 7 (jetzt Abb. 6) durch eine neue Fassung ersetzt.

Die Online-Version des Originalartikels ist unter https://doi.org/ 10.1007/s10010-018-0263-3 zu finden.

\footnotetext{
Dominik Schittenhelm

dominik.schittenhelm@bmw.de

1 BMW Group, Ohmstraße 2, 84030 Landshut, Deutschland

2 Fraunhofer-Institut für Fertigungstechnik und Angewandte Materialforschung IFAM, Wiener Str. 12, 28359 Bremen, Deutschland
} 